\title{
Crisis management: Planning for the inevitable
}

\author{
Niyaz Aboudzadeh $^{\mathrm{a}^{*}}$, Abdolhamid Hajipoor Shoshtari ${ }^{\mathrm{b}}$ and Shahram Hashemnia $^{\mathrm{c}}$
}

${ }^{a}$ Masters Student, Department of Business Management, Payame Nour University, POBox 3148834183, Tehran, Iran

${ }^{b}$ Assistant Professor, Department of Business Management, Payame Nour University, POBox 3148834183, Tehran, Iran ${ }^{c}$ Assistant professor, Department of Management, Payame Nour University, POBox 193953697, Tehran, Iran

\section{H R O N I C L E A B S T R A C T}

\begin{tabular}{l}
\hline Article history: \\
Received December 28, 2013 \\
Accepted 4 May 2014 \\
Available online \\
May 8 2014 \\
\hline Keywords: \\
Crisis management \\
Mapna \\
Strategy
\end{tabular}

The aim of this study is to identify important factors influencing organizational readiness to deal with the crisis in business organizations. The study designs a questionnaire in Likert scale and distributes it among some experts who work for Mapna company in Iran. The study uses the method developed by Mitroff (2005) [Mitroff, I. I. (2005). Why some companies emerge stronger and better from a crisis: 7 essential lessons for surviving disaster. AMACOM Div American Mgmt Assn.], which investigates the effects of four factors including job satisfaction, increase in income, cost reduction and change in strategies on crisis management. Using Pearson correlation ratio, the study has confirmed a positive and meaningful relationship between crisis management and three factors including increase in income, cost reduction and change in strategies. However, the study did not find any evidence to support the relationship between job satisfaction and crisis management.

\section{Introduction}

There is an agreement among economists on common measures influencing on economic recession and crisis (Booth, 1993; Pearson \& Clair, 1998). These measures include building as well as managing capital structure in such a way to cover expenses of long-term losses and expensive loan payments, preventing borrowing to finance the losses, being cautious on the implementation of longterm bank loans only for long-term loan needs, etc. There are many firms, in the world, that outlast and increase their market shares and profits through changing their business model. There are serious problems and possible barriers as a boon for creativity and innovation in business model. Ucaktürk et al. (2011) determined the failure causes of enterprises in business model innovation. They also investigated whether possible actions such as crisis and recession periods, economic stagnation, lucratively could help enterprises cope with difficult economic conditions.

*Corresponding author.
E-mail addresses: aboudzadeh.niyaz@gmail.com (N. Aboudzadeh) 
Several firms may face with organizational declines at some point in their life cycles because of both external and internal factors. As an alternative strategy to the times of crisis, operating turnaround strategies are targeted to include a company's chances of ending the threat and reaching sustainable performance recovery.

Tikici et al. (2011) determined whether or not operating turnaround strategies were applied by manufacturing companies operating in Malatya to cope with recent global crisis. According to Valackiene (2011), to manage the crisis within business environment, it is necessary to consider the process of crisis planning, as well as strategy management within a particular firm. To reach that a sufficient training of staff is essential, in addition to that the analysis of the situation and search for alternative solutions are needed. To get prepared for a crisis planning and strategy management process, both scholarly discussions and practical solutions are also essential. Action planning helps management not only to assess the dynamics within a business environment, but also helps become familiar with similar changes.

Valackiene (2011) analyzed the solutions of strategic changes, specifying crisis communication in a firm and employee's self-identification. They reported that it is always necessary to revise the strategy of a particular firm, which had been executed and demonstrated various approach of the crisis management in an organization and modified a new strategic determination. According to Valackiene (2010), many business leaders agree that all companies experience crisis but do know who to apply any actions to overcome it. Therefore, crisis problems may not be solved in its early stage and usually chaotic, without any strategic crisis situation or crisis management plans. Myer et al. (2007) investigated human impact issues for crisis management in organizations.

According to Altiok (2011), there has been tremendous awareness and a requirement that vision and mission must not merely be a written slogan to serve as a symbol the firm to reach its objectives, but rather be "applicable". A shared and applicable vision formed with participation from all employees, empowers a firm to reach desirable objectives and succeed. An applicable vision gains the firm a long-term perspective, concentrates it to its goals, and provides necessary motivation for its workers and synergy for the whole firm. An applicable vision is essential in terms of building a firm culture, which is stronger against crises. The vision being applicable, on the other hand, holds together the employees as for them to realize their objectives, also motivating them, and thus forms in the mind the necessary changes for an enthusiastic future. Visions, which are formed together turn the sharers into strategic partners, which directs decision making, and provides solidity, thus competitive advantage, to the firm in highly uncertain transition periods, such as crisis times. Ashcroft (1997) investigated the crisis management-public relations.

\section{The proposed study}

The aim of this study is to identify important variables influencing organizational readiness to deal with the crisis in business organizations. The study designs a questionnaire in Likert scale and distributes it among some experts who work for Mapna company in Iran. The study uses the method developed by Mitroff (2005), which investigates the effects of four factors including job satisfaction, increase in income, cost reduction and change in strategies on crisis management. The sample size is calculated as follows,

$n=\frac{N \times z_{\alpha / 2}^{2} \times p \times q}{\varepsilon^{2} \times(N-1)+z_{\alpha / 2}^{2} \times p \times q}$,

where $N$ is the population size, $p=1-q$ represents the yes/no categories, $z_{\alpha / 2}$ is CDF of normal distribution and finally $\varepsilon$ is the error term. Since we have $p=0.5, z_{\alpha / 2}=1.96$ and $N=5852$, the number of sample size is calculated as $n=360$. In our study, we have distributed 380 questionnaires and 
managed to collect 355 propely filled ones. The questionnaire consists of 76 questions in Likert scale where seven questions are associated with personal characteristics of the participants. In addition, the survey uses 46 questions from the survey accomplished by Tikici et al. (2011) where 25 questions are associated with job satisfaction, 9 questions are related to revenue increase and 12 questions are associated with cost reduction. In addition, there are 14 questions associated with change in strategy, which was adopted from Ucaktürk's survey (Ucaktürk et al., 2011). Finally, there are 12 questions associated with preparation of crisis management, which was designed by researchers. Fig. 1 shows details of the personal characteristics of the participants.

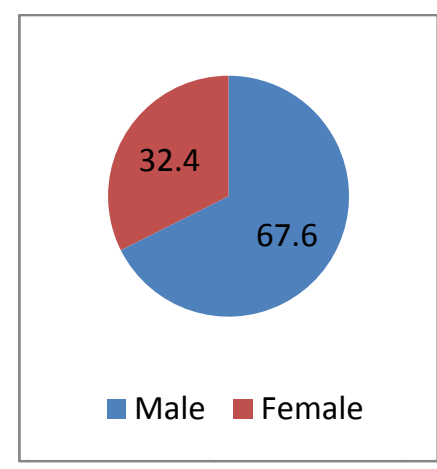

Gender

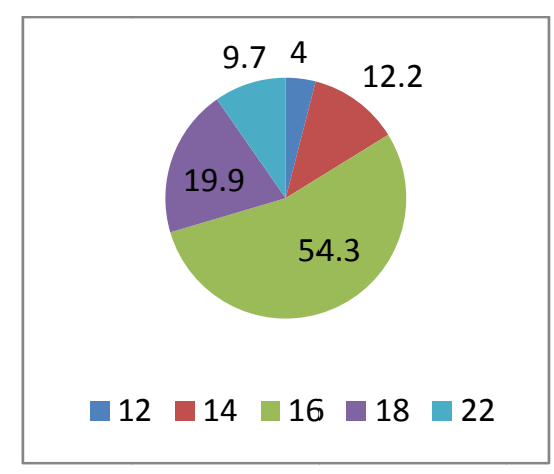

Years of educations

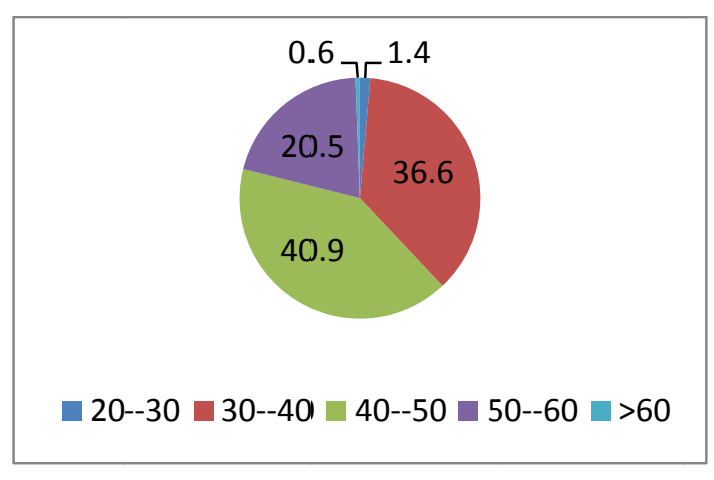

Age

Fig. 1. Personal characteristics of the participants

In terms of gender, two-third of the participants was male and in terms of educational background, most of them hold bachelor degrees of science, mostly on engineering field. In our survey, most participants were middle age and with good job experiences. Cronbach alpha has been calculated as 0.89 , which is well above the minimum acceptable level. Fig. 2 shows the proposed study of this paper.

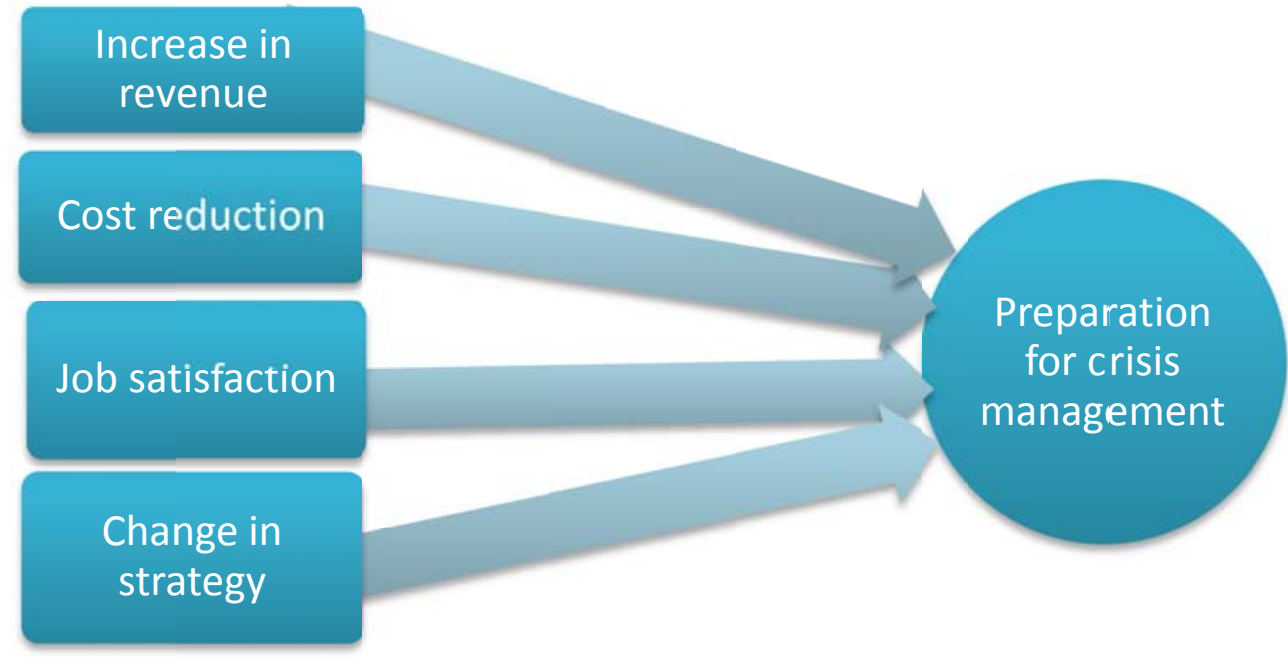

Fig. 2. The proposed study

Based on the proposed study, we present the main hypothesis of the survey as follows,

Main hypothesis: There is a meaningful relationship between the factors reducing crisis management and preparation for crisis management. 
In addition, there are four sub-hypotheses associated with the study as follows,

1. There is a meaningful relationship between Job satisfaction and preparation for crisis management.

2. There is a meaningful relationship between increase in revenue and preparation for crisis management.

3. There is a meaningful relationship between cost reduction and preparation for crisis management.

4. There is a meaningful relationship between change in strategy and preparation for crisis management.

The implementation of Kolmogorov-Smirnov test indicates that the data were normally distributed and we therefore use Pearson test to verify the hypotheses of the survey.

\section{The results}

In this section, we present details of our findings on testing various hypotheses of the survey. In order to test the main hypothesis of the survey, we have used Fisher test between the dependent variable, preparation for crisis management, and independent variables. In our survey, F-value is equal to 12.3 with P-value $=0.000$, which means there was a meaningful relationship between these two components. Therefore, the main hypothesis of the survey has been confirmed.

\subsection{The first sub-hypothesis: The effect of Job satisfaction}

In our survey, the Pearson correlation ratio between job satisfaction and preparation for crisis management is equal to 0.187 with $\mathrm{P}$-value $=0.89$, which means there was no meaningful relationship between these two components and we cannot confirm the first sub-hypothesis of the survey.

\subsection{The second sub-hypothesis: The effect of increase in revenue}

In our survey, the Pearson correlation ratio between increase in revenue and preparation for crisis management is equal to 0.747 with $\mathrm{P}$-value $=0.01$, which means there is a meaningful relationship between these two components and we may confirm the second sub-hypothesis of the survey.

\subsection{The third sub-hypothesis: The effect of cost reduction}

Next, the Pearson correlation ratio between cost reduction and preparation for crisis management is equal to 0.814 with $\mathrm{P}$-value $=0.01$, which means there is a meaningful relationship between these two components and we may confirm the third sub-hypothesis of the survey.

\subsection{The fourth sub-hypothesis: The effect of change in strategy}

Finally, the Pearson correlation ratio between cost reduction and preparation for crisis management is equal to 0.714 with $\mathrm{P}$-value $=0.01$, which means there is a meaningful relationship between these two components and we may confirm the last sub-hypothesis of the survey.

\section{Conclusion}

In this survey, we have performed an empirical investigation to study the effects of various factors on preparation for crisis management in one of project-based organizations in Iran named Mapna. There is no doubt that such organization may face various crises due to economic or political issues including embargo, change in government, etc. Therefore, it is necessary to find important factors influencing crisis management. Based on the results of our survey, cost reduction is one of the most 
important factors influencing preparation of crisis management followed by revenue increase and change in strategy. The results of our survey are consistent with findings of Mitroff (2005), Tikici et al. (2011), Ucaktürk et al. (2011) and Frandsen and Johansen (2011). Crisis is not always a threats and we may turn it into positive consequences.

According to Bourletidis (2013), in the event of prolonged economic crisis the firms and especially the SMEs ones are influenced, negatively. There are several signs such as the decrease of sells, the shrink of profits, the indulgence of financing, the difficulty of covering the obligations towards the suppliers. Many studies indicate that there have been still some sectors that have been influenced significantly from the financial crisis, there are firms, which show a remarkable yield and it appears that they get a benefit from the crisis and make apply of chances. The difference of the firms' attribution still observed in the same geographical region even though to the same local market.

Johansen et al. (2011) reported a strong relationship between organizational size and crisis management. In other words, the larger the organization, the more likely to face a crisis plans. This specifically pertained to the private firms. Johansen et al. (2011) gave some insights on the role of internal crisis management and crisis communication before, during and after an organizational crisis and/or a societal crisis leading to downsizing or major changes within firms and the results have indicated that crisis is something that could be managed, properly.

\section{Acknowledgement}

The authors would like to thank Mapna's employees who cordially cooperated with the accomplishment of this project. We would like to also express our special thanks to anonymous referees for constructive comments on earlier version of this paper.

\section{References}

Altık, P. (2011). Applicable vision, mission and the effects of strategic management on crisis resolve. Procedia-Social and Behavioral Sciences, 24, 61-71.

Ashcroft, L. S. (1997). Crisis management-public relations. Journal of Managerial Psychology, 12(5), 325-332.

Booth, S. (1993). Crisis management strategy. London, Routledge.

Bourletidis, K. (2013). The strategic management of market information to SMEs during economic crisis. Procedia-Social and Behavioral Sciences, 73, 598-606.

Frandsen, F., \& Johansen, W. (2011). The study of internal crisis communication: towards an integrative framework. Corporate Communications: An International Journal, 16(4), 347-361.

Johansen, W., Aggerholm, H. K., \& Frandsen, F. (2012). Entering new territory: A study of internal crisis management and crisis communication in organizations. Public Relations Review, 38(2), 270-279.

Myer, R. A., Conte, C., \& Peterson, S. E. (2007). Human impact issues for crisis management in organizations. Disaster Prevention and Management,16(5), 761-770.

Mitroff, I. I. (2005). Why some companies emerge stronger and better from a crisis: 7 essential lessons for surviving disaster. AMACOM Div American Mgmt Assn.

Pearson, C. M., \& Clair, J. A. (1998). Reframing crisis management. Academy of management review, 23(1), 59-76.

Tikici, M., Omay, E., Derin, N., Seçkin, S. N., \& Cüreoğlu, M. (2011). Operating turnaround strategies during crisis periods: a research on manufacturing firms. Procedia-Social and Behavioral Sciences, 24, 49-60.

Valackiene, A. (2010). Efficient corporate communication: decisions in crisis management. Inzinerine Ekonomika-Engineering Economics, 21(1), 99-110.

Valackiene, A. (2011). Theoretical substation of the model for crisis management in organization. Engineering Economics, 22(1), 78-90. 
Ucaktürk, A., Bekmezci, M., \& Ucaktürk, T. (2011). Prevailing during the periods of economical crisis and recession through business model innovation. Procedia-Social and Behavioral Sciences, 24, 89-100. 